\title{
High-precision local gravity survey along planned motorway tunnel in the Slovak Karst
}

\author{
Pavol ZAHOREC ${ }^{1}$, Juraj PAPČO ${ }^{2}$, Peter VAJDA $^{1}$, Stanislav SZABÓ ${ }^{3}$ \\ ${ }^{1}$ Division of Geophysics, Earth Science Institute, Slovak Academy of Sciences, \\ Dúbravská cesta 9, P. O. Box 106, 84005 Bratislava, Slovak Republic; \\ e-mail: zahorec@savbb.sk \\ ${ }^{2}$ Department of Theoretical Geodesy, Faculty of Civil Engineering, Slovak University of \\ Technology, Bratislava, Slovak Republic \\ ${ }^{3}$ DPP s.r.o., Žilina, Slovak Republic
}

\begin{abstract}
Results from a detailed gravity survey realized along the planned highway tunnel in the karstic area of Slovak Karst in the eastern Slovakia are presented. Detailed gravity profiles crossed an area of rugged topography, therefore the terrain corrections played a crucial role in the gravity data processing. The airborne laser scanning technique (LiDAR) was used in order to compile a high-resolution digital terrain model (DTM) of the surrounding area and to calculate terrain corrections properly. The difference between the Bouguer anomalies calculated with an available nationwide DTM and those with new LiDAR-based model can be significant in some places as it is presented in the paper. A new method for Bouguer correction density analysis based on surface data is presented. Special underground gravity measurements in the existing nearby railway tunnel were also conducted in order to determine the mean density of the topographic rocks. The Bouguer anomalies were used to interpret lithological contacts and tectonic/karstic discontinuities.
\end{abstract}

Key words: detailed gravimetry, terrain correction, LiDAR, DTM, Bouguer correction density

\section{Introduction}

Two parallel profiles of detailed gravimetric survey were realized in the frame of the detailed engineering geological and hydrogeological exploration in the area of the planned road tunnel of the R2-highway project RožñavaJablonov nad Turňou. The planned tunnel is situated in a protected area of the Slovak Karst national park characterized by karstic relief. Gravimetry, as a suitable non-destructive geophysical prospecting method was carried out with the objective of verifying the occurrence of tectonic and karst- 
weathered lineaments and lithological interfaces of blocks with diverse rock densities.

Since the gravity profiles cross a rough terrain relief, the critical component in compiling the complete Bouguer anomalies (CBA) are the near-zone terrain corrections (e.g., LaFehr et al., 1988; Schiavone et al., 2009). Recently we have dealt in detail with the topic of computing accurate terrain corrections, especially within the near zone (Zahorec et al., 2010). We have developed and we are continuously enhancing our own software for their computation. The most significant requirement for accurate evaluation of terrain corrections is a detailed digital terrain model (DTM) of the given region. For that sake the nearby vicinity of the survey profiles was imaged by air-borne laser scanning (LiDAR). By comparing the LiDAR-derived DTM with the available detailed DMR-3 model based on scanned topographic maps and covering the whole Slovak territory, it is possible to document the high impact of the used LiDAR derived terrain model on the quality of the resulting complete Bouguer anomalies.

Another important element in compiling the complete Bouguer anomalies, especially in rugged terrain, is the choice of the correct topographic density. The correct choice can be assisted by laboratory density analyses of rock samples from boreholes. However, of great value is the analysis of surface gravimetric measurements themselves (Nettleton, 1939), and moreover, the utilization of underground gravimetric observations (e.g. Hammer, 1950). To precise the estimate of the mean density of rocks of the given region we performed a detailed density analysis based on the approach of Mikuška et al. (2017), as well as we also performed methodological measurements of gravity acceleration in the existing nearby parallel railway tunnel (at the depth of about $200 \mathrm{~m}$ below the surface), at spots where the surface gravimetric profiles cross the railway tunnel (Zahorec and Papčo, 2018).

Based on constraining geological data from boreholes 2D density vertical sections were constructed that helped to finetune the geological and tectonic structure in the area of the planned tunnel.

\section{Site description}

The planned tunnel passes through a region, which geomorphologically belongs to the Inner Western Carpathian Subprovince, the Slovak Ore Moun- 
tains area, the Slovak Karst unit, with subunits of the Silica Plateau and the Horný vrch Plateau. Geological-tectonic structure of the rock massif is complicated (Fig. 1), manifesting distinctive karstification. The Slovak Karst has a typical karst relief with flat plateaus divided by deep gorges with hollows, lapies, abbyses and caves. The rock environment of the tunnel consists of Early-Middle Triassic rocks of the Silica and Horný vrch plateaus of the Silica Nappe and of Quaternary deluvial-proluvial sediments. The central part of the investigated area is built by massive light-coloured, organogenic, in some places brecciated limestones (mainly Wetterstein and Steinalm types) with karstification features. Less prominent are carbonates of the Gutenstein formation. The marginal parts of the investigated area are built by Szin Beds represented by shales and marlstones that are weakly metamorphosed (phyllitic schists). The Bódvaszilas Beds (schists and sandstones) form the SE part of the region. Both geological and tectonic settings in the investigated area are very complex. We found out that the boundary between Szin and Gutenstein Formation is tectonic. The Gutenstein limestones/dolomites of Silicicum are displaced north-vergently over the Szin

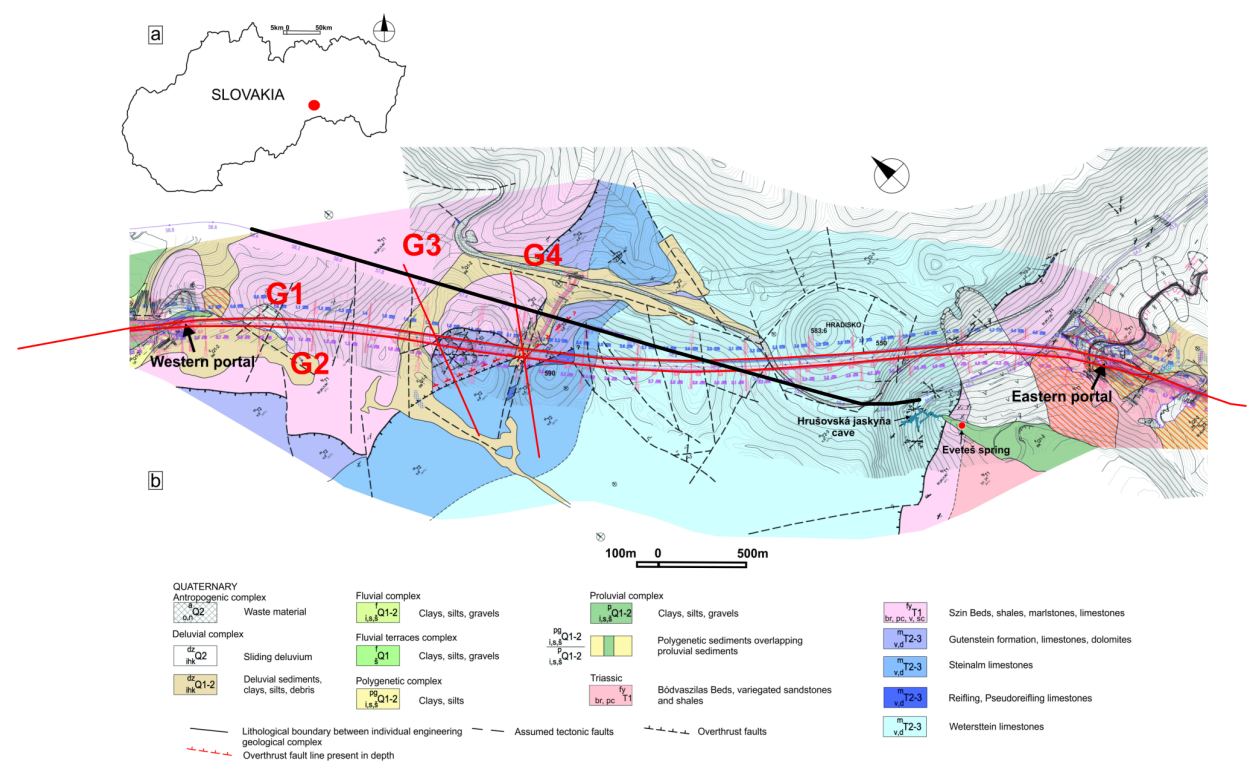

Fig. 1. Engineering geological map of the area (Szabó in Grenčiková et al., 2018) with the gravimetric profiles (red curves: the long profiles G1 and G2 are situated along the planned road tunnel tubes) and the trajectory of the railway tunnel (thick black curve). 
Beds belonging probably to Turnaicum. The most distinct fault systems in the tunnel area are those of NE-SW and E-W, as well as ESE-WNW direction dipping to the NW and N, fault systems of NW-SE direction dipping to the $\mathrm{NE}$ and fault systems of $\mathrm{N}-\mathrm{S}$ direction dipping to the $\mathrm{W}$ and also to the E (Fig. 1). The trajectory of the tracer currents carried away by groundwater currents from the exploration borings towards the Eveteš groundwater source and springs in the Krásnohorska Dlha Lúka locality, that are present along the tunnel route, was due to the NW-SE and E-W, as well as ESE-WNW trending faults.

At a distance of $2.1 \mathrm{~km}$ from the western side of the Soroška tunnel, the Szin Beds are tectonically reduced along a steep S-vergent overthrust zone trending $\mathrm{E}-\mathrm{W}$ to ESE-WNW and dipping to the N, on which Werfenian rocks (Szin Beds) were displaced over the limestone massif. This overthrust zone is permeable and filled with water, (Szabó et al., 2018).

The investigated area had been covered by gravimetric mapping in the scale 1:25 000 (4-6 points $/ \mathrm{km}^{2}$ ) conducted in the period 1965-1975 (Bárta et al., 1969 in Steiner et al., 1991). Regional profile gravimetric measurements in a wider vicinity of the investigated area were performed as a part of the project by Steiner et al. (1991). These are, however, of insufficient detail and do not directly reach into our area.

\section{Data acquisition and processing}

Profile gravimetric measurements were carried out with the step of $10 \mathrm{~m}$ totalling $12 \mathrm{~km}$ during two observation campaigns. In the first campaign measurements along the two main profiles G1 and G2 were performed above the two projected tunnel tubes. Based on the preliminary results of the first campaign additional measurements of the second campaign were proposed in the form of lateral transverse verification profiles G3 and G4 (Fig. 1).

Positioning of the profile gravimetric stations was conducted by the combination of terrestric measurements (the spatial polar method) by means of the total station Trimble S8 and GNSS measurements (RTK VRS method using the SKPOS service, http://www.skpos.gku.sk/en/) by means of the Trimble R10 rover (receiver). GNSS observations of at least $20 \mathrm{sec}$ were taken at each point. The observations were taken in the frame of the ETRS-89 coordinate system and subsequently transformed by the official 
transformation procedure (http://skpos.gku.sk/en/o-skpos.php\#uvod) into the Slovak national reference system S-JTSK coordinate system, realisation JTSK03. Ellipsoidal heights were transformed to the physical heights (Molodenski normal heights) in Baltic vertical reference system 1957 using the Slovak official quasigeoid model DVRM (Klobušiak et al., 2005).

Horizontal positions and heights of the majority of the gravimetric points were determined with the accuracy of or better than $0.04 \mathrm{~m}$. Heights above sea level of the gravimetric points range from about 246 to $613 \mathrm{~m}$ a.s.l.

\subsection{Airborne laser scanning - LiDAR}

For the sake of accurate terrain correction calculation in the nearest vicinity of the gravimetric points the region of interest with an area of $6.4 \mathrm{~km}^{2}$ was scanned by airborne laser scanning technology with the Trimble Harrier 68 system. Processing, adjustment, and filtering of the whole point cloud to the points located on the ground relief (classification "ground") was carried out in software package LAStools v. 170322 (https://rapidlasso.com/las tools/). The average point density on the ground reached 12 points $/ \mathrm{m}^{2}$.

The Digital Surface Model (DSM, including vegetation and man-made objects) and the Digital Terrain Model (DTM, needed for terrain correction calculations) were created in software package Surfer v. 13 (https://www . goldensof tware.com/products/surfer), with kriging method using a step of $0.5 \mathrm{~m}$, see Fig. 2 .

The height accuracy of the resulting model was verified by a set of independent ground control points as well as by gravimetric points. Ground control points were distributed uniformly over the entire scanned region on the site. The differences between the directly observed height and the height interpolated from the DTM at these control points agree at the majority of points to within $0.05 \mathrm{~m}$, which points to a very high quality of the created DTM. Height differences at the majority of gravimetric points are within $\pm 0.15 \mathrm{~m}$. Greater differences occured at points in heavily vegetated locations, or at spots with more extremely rough relief (grikes) and at the margins of the region of interest.

The DTM (Fig. 2 right) served not only for computation of precise terrain corrections, but also for very detailed geomorphologic evaluation of the region, identification of local karst phenomena and tectonic features, etc. 
Fig. 3 shows the comparison of our LiDAR-derived DTM with the available nationwide detailed model DMR-3 with the resolution of $10 \mathrm{~m}$ (based on scanned topographic maps, TOPÚ, 2012).
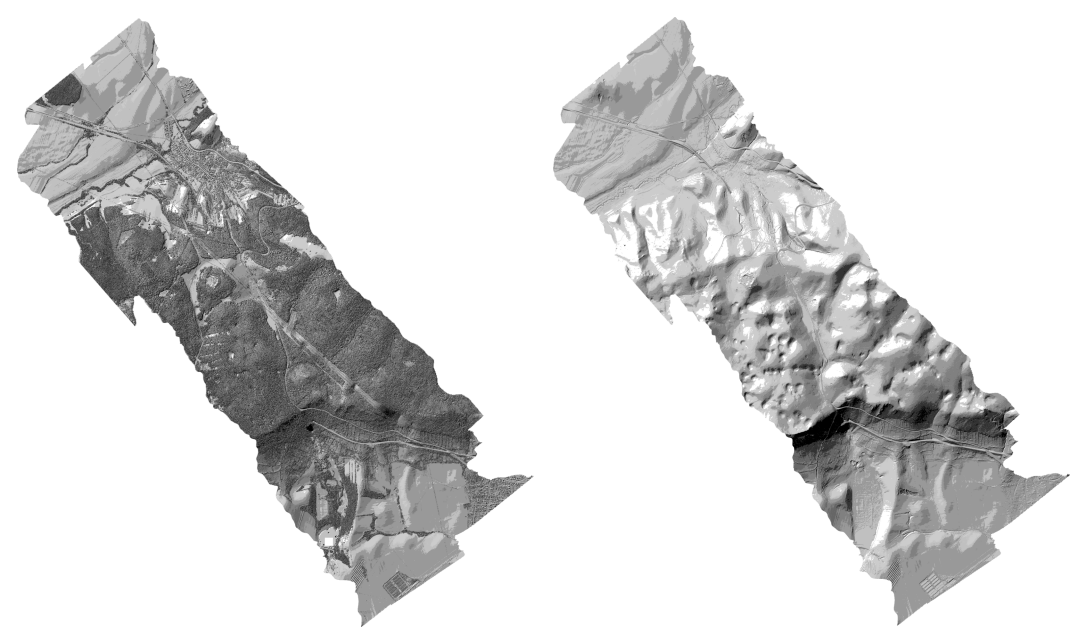

Fig. 2. Comparison of the LiDAR-derived Digital Surface Model (left) and the Digital Terrain Model (right) in our region.

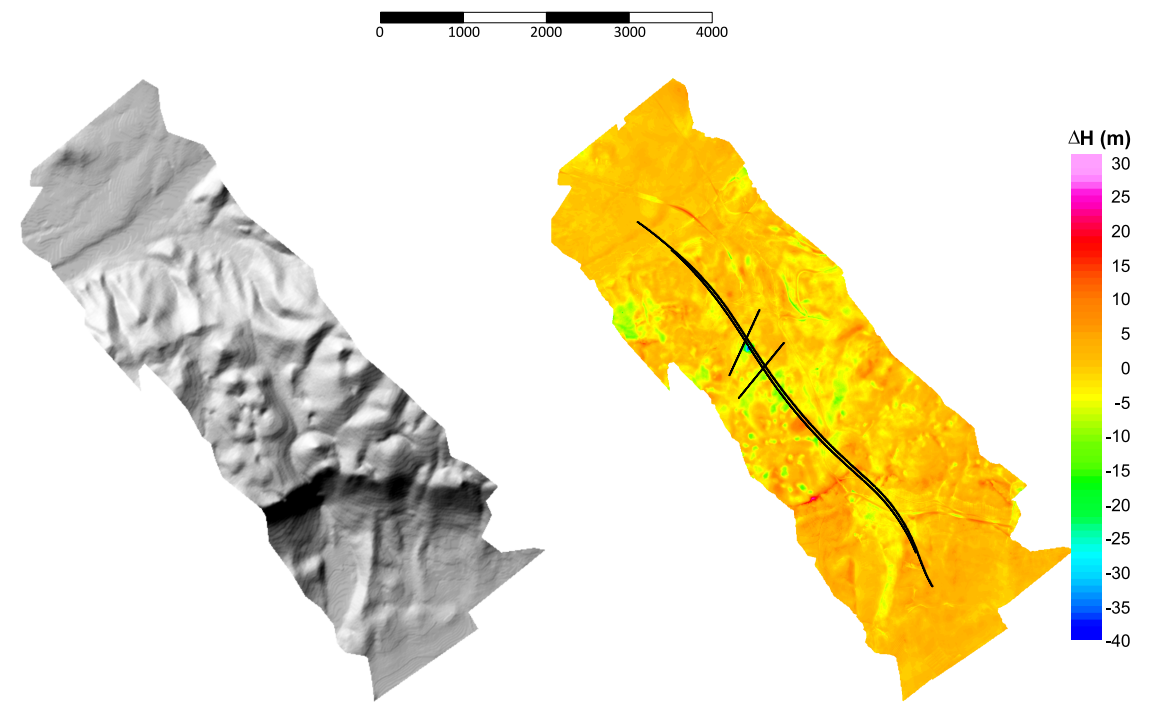

Fig. 3. The available nationwide model DMR-3 (left) and its vertical deviation from the LiDAR DTM (right, cf. Fig. 2). Black curves indicate the gravimetric profiles. 


\subsection{Gravity data}

The measurements of gravity acceleration were carried out by means of the relative gravimeter Scintrex CG-5 during 14 field days in the period November 2016 - April 2017. The measurement were tied two or three times a day to a reference point (situated in the middle of the survey region, easily accessible by car) for the purpose of controlling the drift of the gravimeter. The reference point was tied to the state gravimetric network (point No. 3834.01 Hrhov). The observed gravity values are hence referenced in the valid National reference gravimetric system S-Gr95. The residual daily drifts during our observations (calculated based on repeat measurements at the reference point) ranged from 10 to $60 \mu \mathrm{Gal}$ per day. During each observation day repeated measurements were conducted also at selected gravimetric points on the profiles (about 10\% of the overall points) that served for calculating the measurement error. The standard deviation was determined from these repeated measurements at the level of $\pm 10 \mu \mathrm{Gal}\left(1 \mu \mathrm{Gal}=10^{-8} \mathrm{~m} / \mathrm{s}^{2}\right)$.

The values of complete Bouguer anomalies (CBA) were calculated based on the standard procedure:

$C B A(P)=g(P)-\gamma\left(P_{0}\right)-\delta \gamma_{F}(P)-\delta g_{s p h}(P)+T(P)+\delta g_{a t m}(P)$,

where $g(P)$ is the observed gravity (corrected for gravimeter drift and tides) in the S-Gr95 gravimetric system, $\gamma\left(P_{0}\right)$ is normal gravity at the level ellipsoid according to the Pizetti-Somigliana formula with parameters of the reference ellipsoid GRS80, $\delta \gamma_{F}$ is the height correction (also called freeair correction) with a second order approximation (Wenzel, 1985 in Torge, 1989), so that $\gamma(P)=\gamma\left(P_{0}\right)+\delta \gamma_{F}(P)$ gives the value of normal gravity evaluated at the observation point, $\delta g_{s p h}(P)$ is the gravitational effect of the spherical cap with radial (spherical) radius $166.7 \mathrm{~km}$ and with thickness equal to the height of the evaluation point $P$ (Mikuška et al., 2006) - the so called Bouguer correction, $T(P)$ is terrain correction and $\delta g_{a t m}$ is atmospheric correction computed according to Wenzel (1985) in Torge (1989) modified for the territory of Slovakia based on an approximation of the gravitational effect of atmospheric masses which takes into account the real topographic relief (Mikuška et al., 2008).

To compute the terrain correction (up to radial distance $166.7 \mathrm{~km}$ from the evaluation point $\mathrm{P}$ ) we used the Toposk software (Zahorec et al., 2017). 

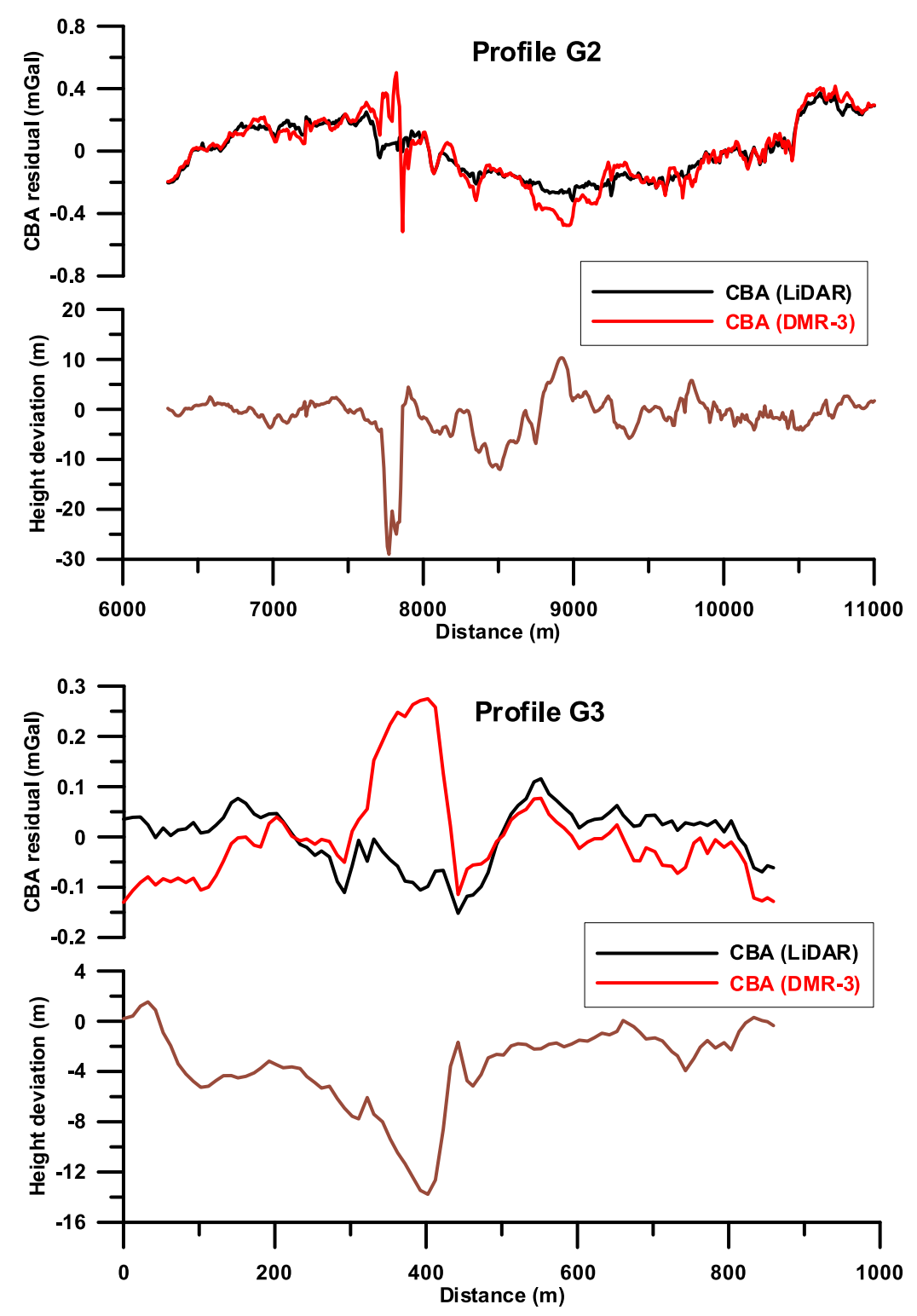

Fig. 4. Two examples of comparison of the residual Bouguer anomalies (upon removal of a linear regional trend, cf. also Fig. 8) computed with terrain corrections T1 from DMR-3 and from LiDAR-DTM. Brown curves are height deviations of gravimetric points from the DMR-3. 
The computation is carried out in the usual way in four zones, whereby in each zone a different DTM is adopted, the closer the zone to the point $P$ the more detailed (the higher the resolution of) the model. For the distant zones T31 $(5.24-28.8 \mathrm{~km})$ ad T32 $(28.8-166.7 \mathrm{~km})$ we used the SRTM (Jarvis et al., 2008) with resolution 3 and 30 arcsec, respectively. For the nearer zones T1 $(0-250 \mathrm{~m})$ and T2 $(250-5240 \mathrm{~m})$ we use standardly the above mentioned detailed model DMR-3 (TOPÚ, 2012), while in the innermost zone we use the concept of interpolated heights, which reduces the computation error originating from the misalignment of DTM with the real height of measured points (Zahorec, 2015). However, for the most accurate computations even this model becomes insufficient. For this reason we have used within the T1 zone the above described DTM obtained from airborne laser scanning. The LiDAR-derived DTM facilitated, as expected, unprecedented accuracy in computing the terrain correction when compared to the use of DMR-3 (Fig. 4). Prominent differences are manifested mainly in the central part of our site, which is characterized by pronounced rough relief (surface mine pit, sinkholes) and in addition it is also forested.

The differences in the computed terrain corrections within T1 (and consequently in CBA) reflect the height deviations of DMR-3 from real heights (brown curves in graphs of Fig. 4). One can see that in critical parts of the profiles significant local false anomalies arise due to the topography deviations. These false anomalies can lead to misinterpretations, as well as to masking the true less pronounced anomalies. Thanks to the roughness of the relief the terrain correction represent the key contribution to the overall interpretation value of the final CBA curves.

\subsection{Bouguer correction density analysis based on gravity mea- surements}

For choosing a proper correction density (used in the Bouguer cap term and in the terrain correction) for computing the CBA, we adopt the well known fact that the profiles cross carbonate rocks (mainly limestones), for which we assume that their mean density does not depart significantly from $2.67 \mathrm{~g} / \mathrm{cm}^{3}$. Laboratory density analyses were performed as a part of the engineering geological and hydrogeological prospection, which indicate slightly higher values of the bulk densities (on average about $2.7 \mathrm{~g} / \mathrm{cm}^{3}$ ). These densities, however, do not account for the contribution of significant karstifica- 
tion (karst-weathering) of the rock environment in this region. Therefore we decided to pay close attention to the analysis of the observed gravity data with the objective of estimating the proper correction density. Our analysis originated from data observed along the profiles as well as from additional underground gravity observations conducted for that sake.

\subsubsection{Surface gravity data analysis}

To estimate the proper correction density, a method arising from visual correlation of CBA curves with topographic relief is often used in practice (Nettleton, 1939). In Fig. 5 this method is illustrated for the profile G1. One can see that the CBA curve for correction density of $2.67 \mathrm{~g} / \mathrm{cm}^{3}$ (black) approximately represents the minimum correlation with the terrain relief compared to other CBA curves (compiled with different correction densities).

A more proper and more accurate method can be opted for, which is based on numerical estimate of the correction density making use of FreeAir Anomalies (FAA) and the values of the topographic effect (the Near Topographic Effect - NTE). This approach again requires a more pronounced rugged terrain relief with sufficient height differences between individual points of evaluation (gravimetric points) and at the same time a high-quality DTM for accurate NTE computation. Fig. 6 shows the dependence of the FAA values on the NTE ones (for the density of $1 \mathrm{~g} / \mathrm{cm}^{3}$ ). The linear regression coefficient corresponds to the value of the sought correction density (Mikuška et al., 2017). One can see that the graph constructed from the original FAA vs. NTE values (Fig. 6a) has two "branches", which is caused by the presence of a regional trend in the original FAA values (and also in CBA values, cf. Fig. 7). The branching of the graph deforms the value of correction density $\left(2.61 \mathrm{~g} / \mathrm{cm}^{3}\right)$, therefore it is necessary to remove the regional trend from the data. The first possibility is to determine the regional trend based on the CBA curve (for the assumed density of $2.67 \mathrm{~g} / \mathrm{cm}^{3}$ ). When we apply the linear trend obtained in such a way to the FAA values, the branching in the graph disappears and the regression coefficient (the correction density) attains a more reliable value of $2.66 \mathrm{~g} / \mathrm{cm}^{3}$ (Fig. 6b).

Another approach to computing regional trend, which we explored, is based on the analysis of the linear tendencies in the FAA and NTE fields 
(Mikuška et al., 2012). The linear regression coefficient determined from the residual values obtained in such way leads to the value of 2.67 (Fig. 6c), which is very close to the preceding one, and at the same time, corresponds to the realistically anticipated correction density value.

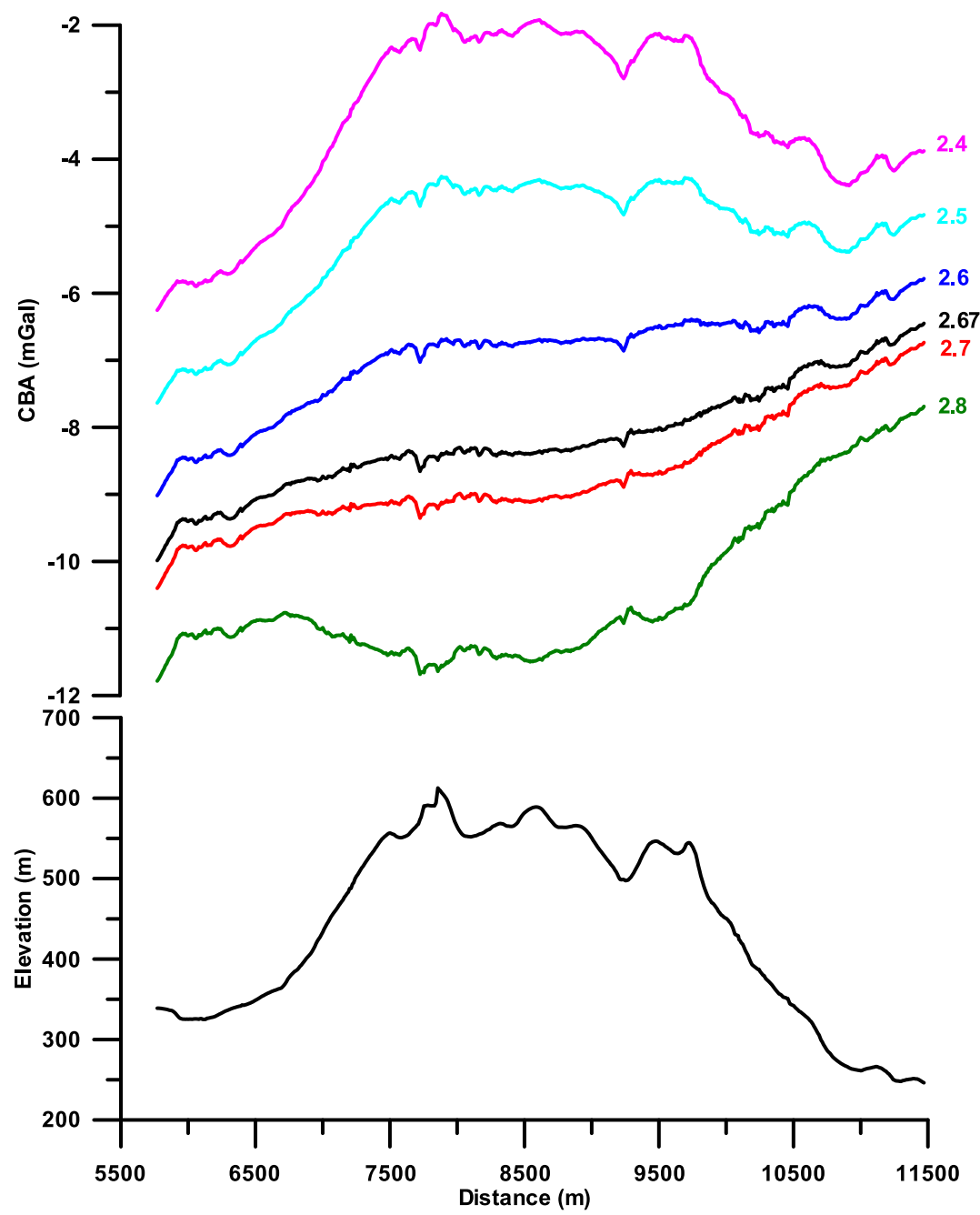

Fig. 5. Approximate selection of the proper correction density based on correlating CBA curves computed for various correction densities (upper graph) with terrain relief (bottom graph) along profile G1. 

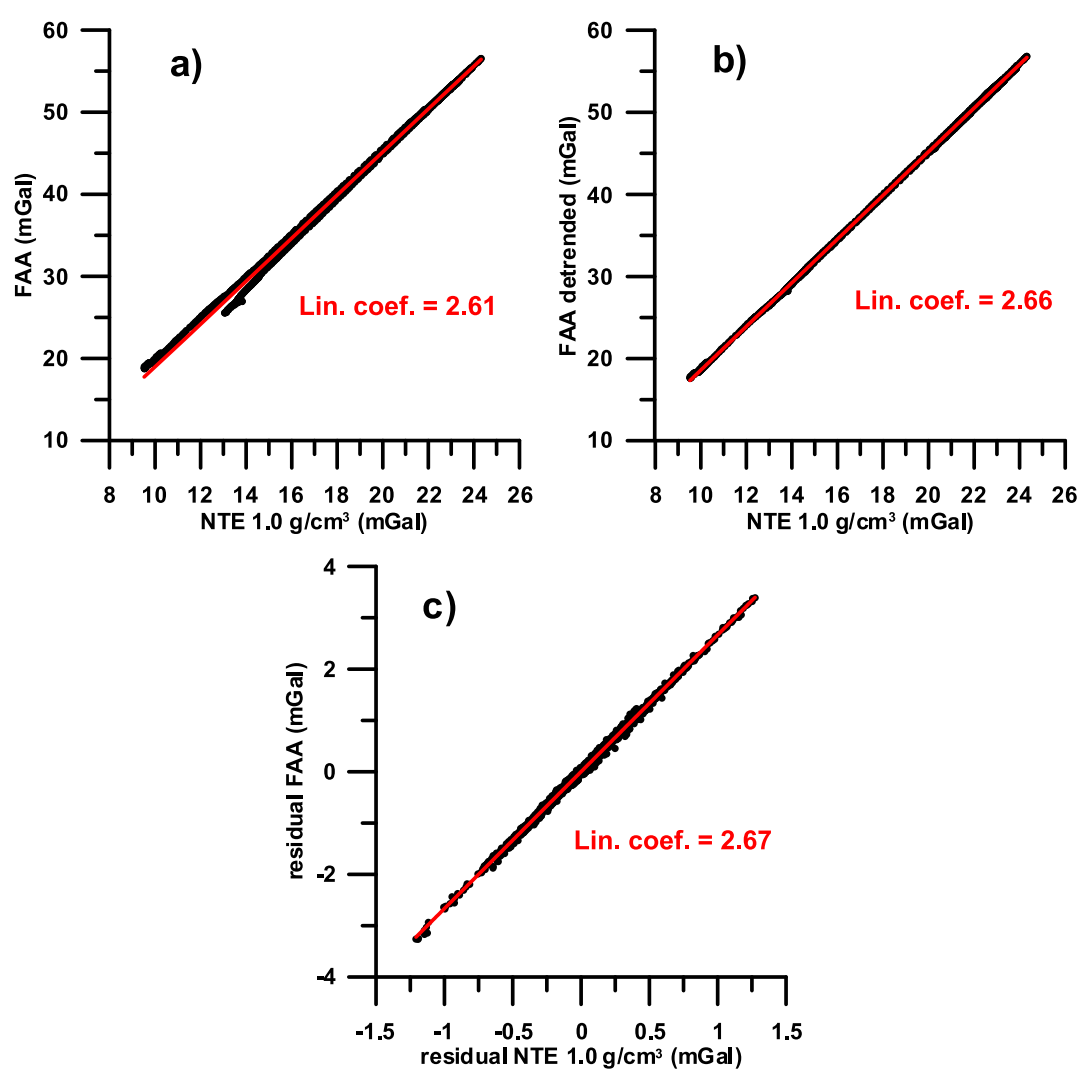

Fig. 6. Estimation of the correction density by means of linear regression coefficient for the dependence of FAA vs. NTE: a) original FAA and NTE values, b) de-trended FAA values (based on regional trend determined from the CBA) and original NTE values, c) residual FAA and NTE values calculated on the basis of the linear tendencies.

\subsubsection{Underground gravity data analysis}

We took advantage of the presence of the nearby Jablonov railway tunnel and utilized it to carry out underground measurements of gravity. The depth of the railway tunnel tube in the spot where it crosses horizontally the main gravimetric profiles (see Fig. 1) is about $200 \mathrm{~m}$ below the surface. This central part of the profiles is respective to geological structure composed of light-grey limestones (Wetterstein limestones) with a lot of karst 
phenomena. Based on the difference between the surface gravity and that at vertically projected points inside the railway tunnel we are able to estimate the mean density of the rock massif inbetween the tunnel level and the surface, upon applying respective corrections to the measured gravity due to the gravitational effects of topography, to the tunnel tube void, as well as to the effect of the normal gradient of gravity (Zahorec and Papčo, 2018). As a result we obtained the value of $2.66 \mathrm{~g} / \mathrm{cm}^{3}$. Compared to the density received from laboratory analyses this value indicates an obvious karstification of this volumetric domain. At the same time this value is
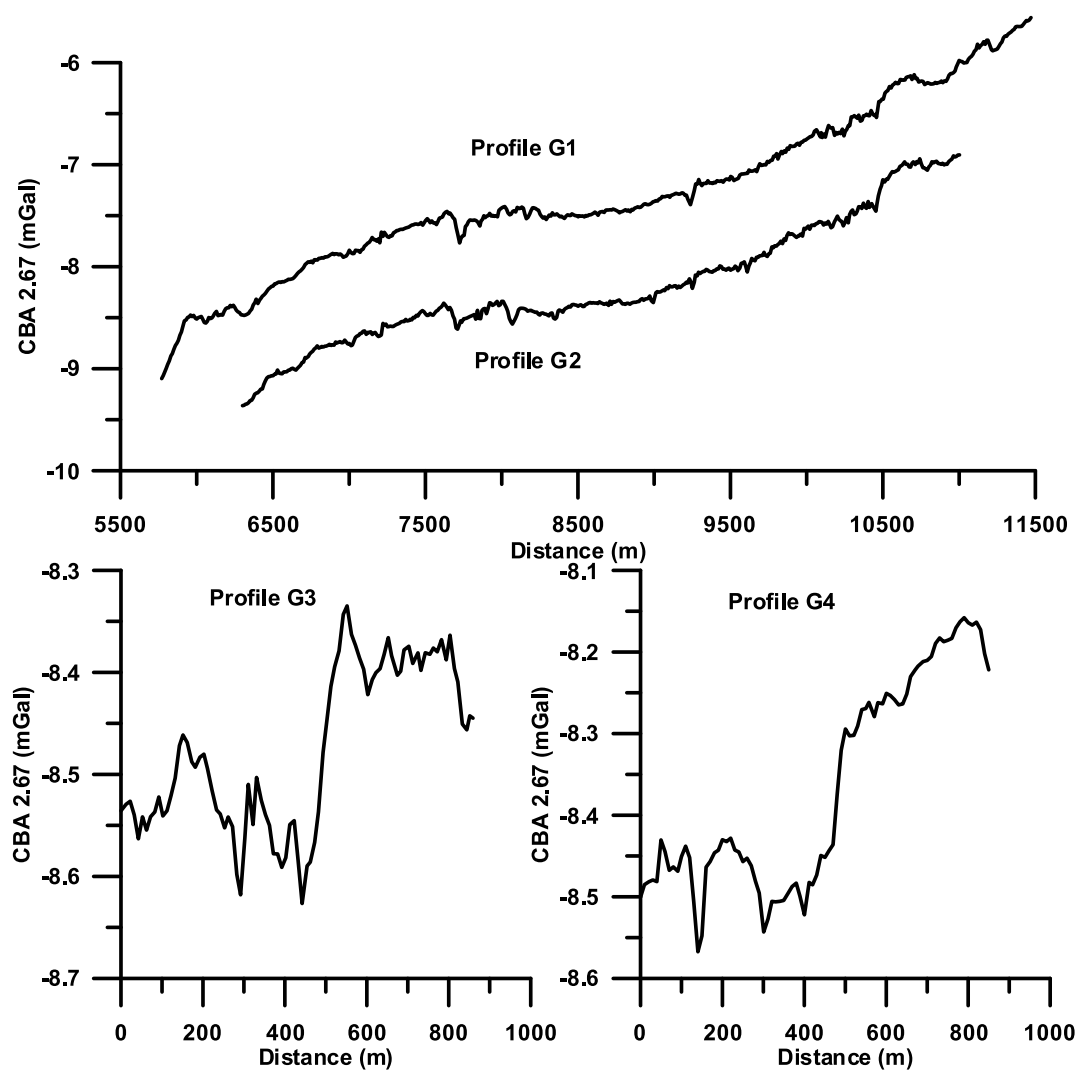

Fig. 7. Complete Bouguer anomaly curves computed with correction density $2.67 \mathrm{~g} / \mathrm{cm}^{3}$. The main profiles G1 and G2 are shown in one graph, but for transparency they are vertically shifted (separated). Note that the additional transverse profiles G3 and G4 have different scales, both vertical and horizontal. 
very close to the density values estimated based on the analyses of surface profile gravity measurements. Taking into consideration all the above mentioned approaches, the correction density of $2.67 \mathrm{~g} / \mathrm{cm}^{3}$ was finally adopted for compilation of the CBA curves and for their subsequent interpretation (Fig. 7).

\section{Interpretation of gravity measurements}

It is clear, upon examining graphs in Fig. 7, that the course of the CBA values along the main profiles G1 and G2 is significantly influenced by a rising regional trend that reflects the deeper geological structure, which is not a part of our subject of exploration. Due to the shape of the curves this regional trend can be approximated by a simple linear function. The removal of the linear trend results in curves of CBA residuals, which constitute the basis for our interpretation (Fig. 8).

The amplitudes of the residual anomalies are very low, at the level of the first tenths of mGal. This is an evidence for the presumed hypothesis that the density differences among the individual rock types in our region of interest are inexpressive. Despite this observation we are able from the qualitative point of view, based on the residual CBA curves, to mark several density (lithological) contacts (interfaces) in the horizontal direction (in the spots of significant gradients in the course of the residual anomalies curves), or alternatively the possible corrupted (weathered, disrupted rock) zones based on the occurrence of sharp local negative anomalies.

A relevant quantitative interpretation can be conducted based on constraining information such as borehole data that facilitate defining approximate spatial geometry of anomalous bodies, to assign geological meaning to them, and to estimate their density parameters, and subsequently to reduce in this way the principal ambiguities of the interpretation. With the help of the said constraining information we have constructed schematic density sections by the method of 2D (profile) density modelling in the Geosoft GM-SYS software environment (https://www.geosoft.com/products/gm -sys), which gives us information about lithological structure and about disruption zones. Since the two profiles are close to each other and their density sections exhibit little differences, we show the interpretation of the densiy model only for the longer northern profile G1. 

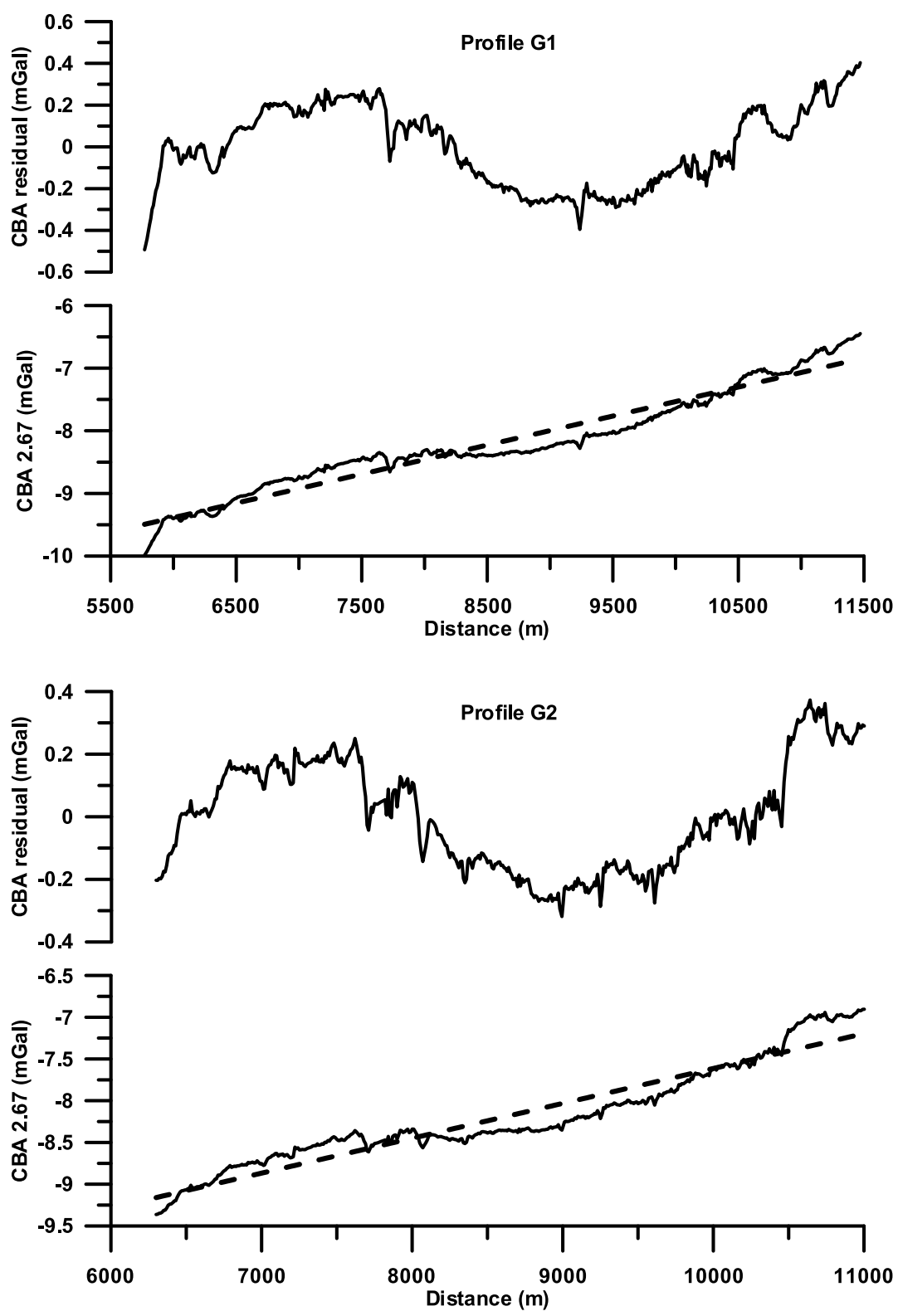

Fig. 8. Residual CBA curves upon removal of linear regional trend (dashed line). 
The additional transverse short profiles G3 and G4 were executed for the purpose of verifying the slanted lithological contact in the spots where the profiles cross (see also Fig. 10). The contacts are manifested by steep gravity gradients in CBA curves (Fig. 7, bottom graphs).

\subsection{Density modelling along profile G1}

On the graph of the residual anomalies (Figs. 8 and 9) one can see that in terms of the whole profile a central wide negative gravity anomaly dominates, which we interpret based on the available geological information as the effect of a robust body of limestones (Wetterstein and Steinalm limestones) affected by karstification. The reduced density of this environment was independently confirmed also by additional subsurface measurements in the nearby railway tunnel. The shape of the contact surface (interface) bordering the surrounding blocks depthwise is finetuned based on information from boreholes. At the eastern side, where this interface is not captured by boreholes, its shape downward is questionable, and we model it as subvertical. We interpret the sharp negative anomaly at footage $9230 \mathrm{~m}$ as a disrupted (karstified) zone within the massif, which correlates with the

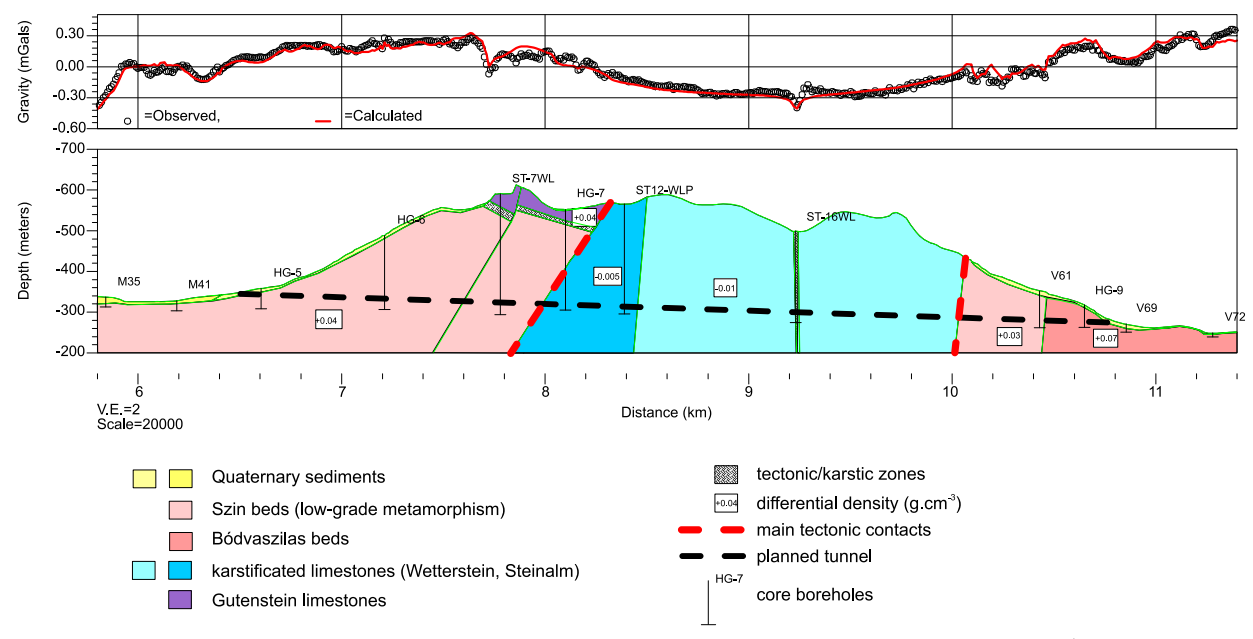

Fig. 9. Cross-section density model of the rock environment along profile G1 (the northern tunnel tube) based on 2D density modelling in GM-SYS software package. Thick red dashed lines indicate the probable tectonic contacts between limestones (Silicicum) and Szin beds (Turnaicum). The vertical scale of the section is magnified by the factor of 2 . 


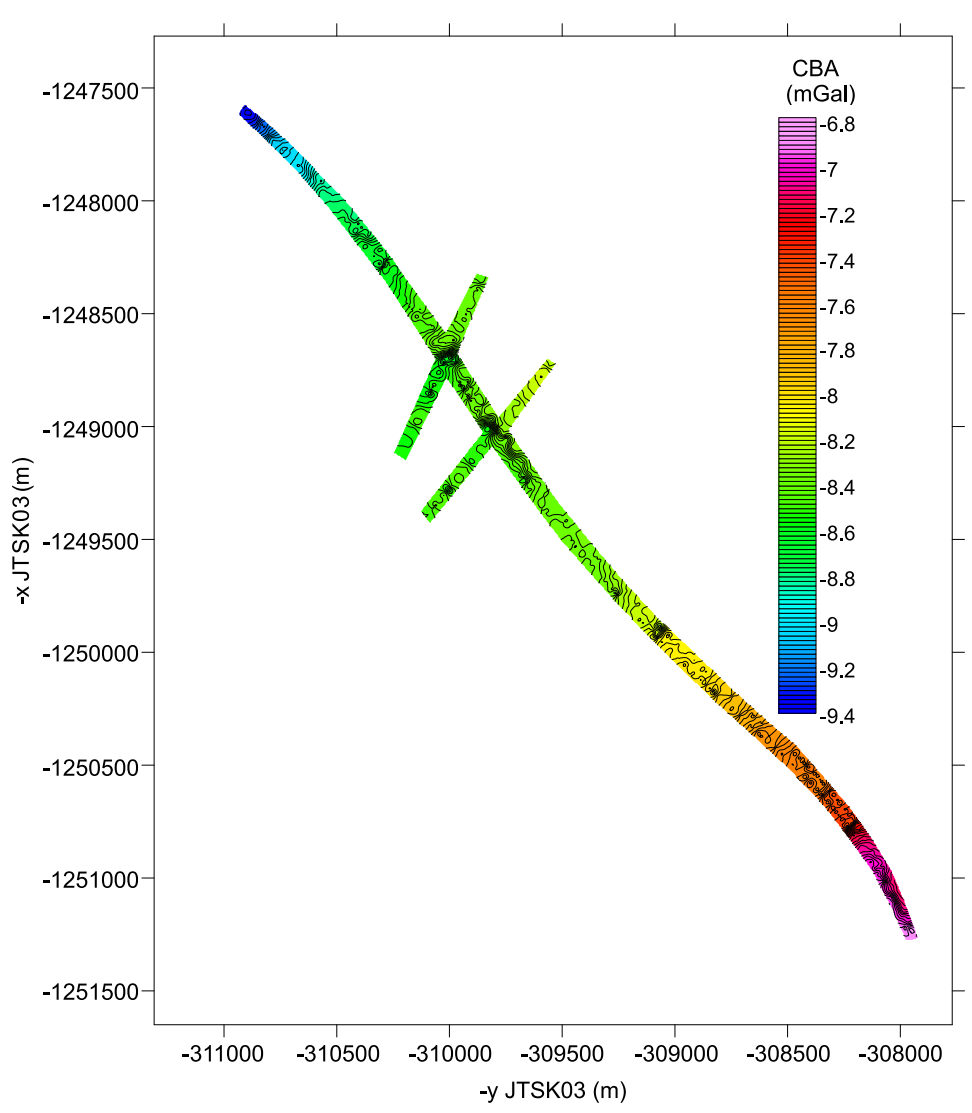

Fig. 10. Quasi-areal map of CBA constructed in the close vicinity of gravity profiles.

occurence of caverns at borehole ST-16WL. The disrupted zone (of W-E elongation) with occurrence of karst phenomena is visible also in the images from airborne laser scanning. The extension of this zone downwards is only schematic.

On both sides of the limestone massif we model bodies with positive differential densities. According to geological cognition they correspond to the so-called Szin beds (marlstones, shales). The reason for their paradoxically higher density relative to the limestones is likely the mentioned karstification of the limestones, and also a low grade of metamorphism of these rocks (phylittic schists), which was revealed by analysis of borehole cores. Our modelling catches a body with the highest differential density 
$\left(+0.07 \mathrm{~g} / \mathrm{cm}^{3}\right)$ paradoxically at the end of the profile (beyond footage of about $10500 \mathrm{~m}$ ). This we more or less attribute to the marginal deformation of the model, since we know that in the superficial parts of this area the so called Bódvaszilas horizons (shales, sandstones) were identified, for which we do not expect (based on analysis of cores) higher density. But we can expect rocks of higher density below these layers.

In the space at the footage interval from about 7700 to $8300 \mathrm{~m}$ we model above the Szin Beds the Gutenstein limestones found in the boreholes. Although we assign to them a slightly higher density $\left(+0.04 \mathrm{~g} / \mathrm{cm}^{3}\right)$, based on published works as well as on borehole core densities, compared to other types of limestones, due to their identified low thickness they have a low gravitational signature. They are significantly tectonically limited from the west (a sharp negative anomaly at around $7720 \mathrm{~m}$ of footage), where we interpret a significant disruption zone. Its downward course we model based on the borehole core results.

From the qualitative viewpoint what is interesting regarding the CBA curve is a steep gravity gradient (rise) at the beginning of the profile (footage of about $5900 \mathrm{~m}$ ). This contact we model by increased thickness of quaternary sediments. However, there is a possibility that it can be caused already by the contact with Neogene filling of the basin.

We interpret several less pronounced negative anomalies along the profile (at about 6200 to $6500 \mathrm{~m}$, then 10700 to $11000 \mathrm{~m}$, and also 11200 to $11300 \mathrm{~m}$ ) by a varying thickness and character of of quaternary sediments, which despite their low thicknesses generate measureable effects, as we assign to them high differential densities $\left(-0.5\right.$ to $\left.-0.7 \mathrm{~g} / \mathrm{cm}^{3}\right)$, the highest among all lithological types.

We can make use of the fact that the profiles run close to each other. We correlate between them the more pronounced density contacts to gain an idea about their course in horizontal direction. In Fig. 10 we show the quasi-areal map of the CBA constructed based on measurements along all profiles (including the transversal ones), which yields in the close vicinity of the profiles quasi-areal information about the course (shape) of density interfaces, based on the course (shape) of the isolines. Of course we emphasize that this is very limited areal information and it is not possible to extrapolate it outside of the close vicinity of the gravity profiles. Despite its limitation, such areal view yielded several interesting additional pieces 
of information. For instance the course (shape) of isolines between profiles G1 and G2 in spots where the transversal profiles cross indicated that at those spots the density interfaces are either in oblique or in sub-parallel orientation to the profiles, which was one of the reasons to select the location of the transverse profiles at these spots. Similar is the situation at the SE margin of the profiles, where the course (shape) of the isolines also indicates a parallel course of density interfaces, which has been documented also in existing boreholes. Such knowledge reinforces the awareness of weaknesses of the 2D modeling approach at such spots where the model can deviate significantly from reality.

\section{Conclusions}

The presented results of the detailed gravimetric exploration in demanding rugged karst terrain demonstrated the potential of detailed interpretation when using a modern approach to computing terrain corrections based on a DTM acquired by airborne laser scanning (LiDAR) of the surrounding region. Terrain corrections have proved to be the key factor from the viewpoint of the quality of processing and interpretation of gravimetric observations in mountainous or hilly terrain. Another important aspect is the choice of proper correction density for computing the complete Bouguer anomaly (CBA). A detailed density analysis of surface gravity data based on correlating the free air anomalies (FAA) with the topographic effect yields reliable estimate of the correction density, whereby it is in agreement with the classical method according to Nettleton. The underground gravity observations carried out in a nearby parallel railway tunel proved to be an independent confirmation of the correctness of the selection of the correction density. All of the applied approaches confirmed that the assumed density of $2.67 \mathrm{~g} / \mathrm{cm}^{3}$ was correct. In addition, this finding confirmed the well known fact that the estimate of the correction density acquired in this way may disagree with the results of laboratory density analyses of rock samples.

The results of 2D density modelling supported by borehole data yielded information about density (lithological) properties, as well as about assumed disruption zones en-route the planned Soroška tunnel trajectory. As the most significant finding of our exploratory survey we consider the density distinguishing of the blocks of the massive karstified limestones from the 
(weakly metamorphosed) Szin Beds. An important contribution is also the mapping (delineation) of more pronounced zones of disruption that underwent the anticipated karstification. The small mutual separation of the profiles facilitates also areal view (though very limited) on the course (shape) of the investigated interfaces (contact surfaces). This view indicates that the courses (angles) of the lithologic contacts are of a variety of orientations with respect to the course of the planned tunnel. This variety of orientations becomes also a limiting factor for the $2 \mathrm{D}$ approach to modelling.

Acknowledgements. This work was carried out under contract by DPP Ltd. (contract No. I./452/2016/R). This work was partially supported also by Vega grant agency under project No. Vega 1/0462/16. We are grateful to Jana Bučová for her assistance with contract realisation.

\section{References}

Grenčíková A., Szabó S., Copláková J., Majerčák J., Moravanský D., Mitter P., Gaži P., Bučová J., Otruba M., Sklenárová D., 2018: Highway R2 Rožňava - Jablonov nad Turňou. Detailed engineering geological and hydrogeological survey. Final report, DPP, Žilina (unpublished; in Slovak).

Hammer S., 1950: Density determination by underground gravity measurements. Geophysics, 15, 4, 637-652, doi : 10.1190/1.1437625.

Jarvis A., Reuter H. I., Nelson A., Guevara E., 2008: Hole-filled SRTM for the globe Version 4, available from the CGIAR-CSI SRTM 90m Database: http://srtm.csi.cgi ar.org.

Klobušiak M., Leitmanová K., Ferianc D., 2005: Realization of obligatory transformation between national coordinates and height reference system into ETRS89. Proceedings of the International Conference Tatry 2005 (in Slovak).

LaFehr T. R., Yarger H. L., Bain J. E., 1988: Comprehensive treatment of terrain corrections with examples from Sheep Mountain, Wyoming. 58th Ann. Internat. Mtg., Soc. Explor. Geophys., Expanded Abstacts, 361-363, doi: 10.1190/1.1892191.

Mikuška J., Pašteka R., Marušiak I., 2006: Estimation of distant relief effect in gravimetry. Geophysics, 71, J59-J69, doi: 10.1190/1.2338333.

Mikuška J., Marušiak I., Pašteka R., Karcol R., Beňo J., 2008: The effect of topography in calculating the atmospheric correction in gravimetry. SEG Las Vegas 2008 Annual Meeting, SEG Technical Program Expanded Abstracts, 784-788.

Mikuška J., Marušiak I., Pašteka R., Bielik M., 2012: Linear tendencies intrinsic to the Bouguer anomalies in areas of topographic relief. SEG Las Vegas 2012 Annual Meeting, SEG Technical Program, Expanded Abstracts, 1-5. 
Mikuška J., Zahorec P., Papčo J., Karcol R., Marušiak I., 2017: Surface rock density interpretation from detailed gravity measurements based on free-air anomalies and near topographic effects in a terrain with sufficient relative relief. XII Slovak Geophysical Conference, 28-29 September, 2017, Bratislava (oral, abstract).

Nettleton L. L., 1939: Determination of density for reduction of gravimeter observations. Geophysics, 4, 3, 176-183, doi: 10.1190/1.0403176.

Schiavone D., Capolongo D., Loddo M., 2009: Near-station topographic masses correction for high-accuracy gravimetric prospecting. Geophys. Prospect., 57, 4, 739-752, doi : 10.1111/j.1365-2478.2009.00799.x.

Steiner A., Kandrík M., Mikuška J., Mello J., Šefara J., Bujňáková M., Gnojek I., Filo M., Kubeš P., Halmešová S., Marušiaková D., Pospíšil L., Zima L., Krčmář B., 1991: Map of geophysical indications and interpretations. Slovenský kras region. Final report, Geofyzika Bratislava s.e., division Spišská Nová Ves (unpublished; in Slovak).

Szabó S., Copláková J., Soták J., Majerčák J., Otruba M., Moravanský D., Mitter P., Gaži P., Bučová J., Grenčíková A., Malík P., 2018: Engineering-geological, geotechnical and hydrogeological parameters of the Soroška tunnel rock sequences. Mineralia Slovaca, 50, 101-124.

TOPÚ - Topographic Institute, 2012: Digital terrain model version 3 (online). http: //www .topu.mil.sk/14971/digitalny-model-reliefu-urovne-3-\%28dmr-3\%29.php.

Torge W., 1989: Gravimetry, W de G, Berlin, New York.

Zahorec P., Pašteka R., Papčo J., 2010: The estimation of errors in calculated terrain corrections in the Tatra Mountains. Contrib. Geophys. Geod., 40, 4, 323-350, doi: 10.2478/v10126-010-0014-4.

Zahorec P., 2015: Inner zone terrain correction calculation using interpolated heights. Contrib. Geophys. Geod., 45, 3, 219-235, doi : 10.1515/congeo-2015-0021.

Zahorec P., Marušiak I., Mikuška J., Pašteka R., Papčo J., 2017: Numerical Calculation of Terrain Correction Within the Bouguer Anomaly Evaluation (Program Toposk), 79-92. In book: Pašteka R., Mikuška J., Meurers B (eds): Understanding the Bouguer Anomaly: A gravimetry Puzzle. Elsevier, ISBN 978-0-12-812913-5.

Zahorec P., Papčo J., 2018: Estimation of Bouguer correction density based on underground and surface gravity measurements and precise modelling of topographic effects - two case studies from Slovakia. Contrib. Geophys. Geod., 48, 4, 319-336, doi: 10.2478/congeo-2018-0015. 